\title{
Effect of sleep duration and physical activity on certain important body composition parameters among medical students
}

\author{
Sarita Modi', Nazeem Siddiqui' ${ }^{2}$, Sukhwant Bose ${ }^{3}$ \\ ${ }^{1}$ Associate Professor, Department of Physiology, Sri Aurobindo Medical College and PG Institute, Indore, \\ Madhya Pradesh, India, ${ }^{2}$ Professor, ${ }^{3}$ Director Professor, Department of Physiology, Convener Regional Training Center \\ MET Sri Aurobindo Medical College and PG Institute, Indore, Madhya Pradesh, India
}

Background: In this highly advanced era and competitive world everyday life offers less time for sleep and physical activity and the result is serious consequences on physical fitness and health of the society and particularly the young generation. Aims and Objectives: The present study was undertaken to find out the influence of sleep deprivation and physical activity on body composition parameters of college students. Materials and Methods: Total 98 students of MBBS $1^{\text {st }}$ professional at Sri Aurobindo Medical College and Post Graduate Institute, Indore of both sexes were recruited for the study. Students were divided as Adequate sleep duration at night ( $A S D N \geq 7$ hours) and Inadequate sleep duration at night (ISDN $<7$ hours) groups Anthropometric measurements were done and information of sleep parameters and physical activity recorded. Body composition analysis was done by Bio-impedance analysis (BIA). Results: Sleep duration was significantly associated with Body fat \%(BF\%) and Body mass index (BMI) in boys but not in girls. There was significant difference in obesity parameters like BF\% and BMI between ASDN and ISDN in both sexes. Significant difference was also observed on comparing Physical activity with BF\% and BMI of entire group. Conclusion: Sleep length is inversely associated with obesity in boys but not in girls. It also affects physical activity which further aggravates obesity.

Access this article online

Website:

http://nepjol.info/index.php/AJMS DOI: 10.3126/ajms.v7i5.14934 E-ISSN: 2091-0576

P-ISSN: 2467-9100

Key words: Sleep duration, Physical activity, BMI, BF\%

\section{INTRODUCTION}

Sleep is physiological process essential to life. It is important for growth, repair, learning and consolidation of memory. ${ }^{1,2}$ It also influences body composition. The association between sleep hours and obesity has been described in epidemiological studies performed in children and adolescents from different regions of Asian, European and American countries. ${ }^{3-5}$ Recent studies indicate that sleep duration is a significant determinant of body composition besides conventional factors like physical activity (PA), dietary habits and genetic inheritance. ${ }^{6,7}$ Obesity is one of the current health problems reducing life expectancy, quality of life and increases the proneness for chronic diseases such as hypertension, hyperlipidemia, type 2 diabetes mellitus, stroke, sleep apnoea heart disease etc. ${ }^{8}$ In the present scenario prevalence of sleep deprivation has increased in parallel with epidemics of overweight and obesity. ${ }^{9}$ On an average, adult needs 7-9 hours of sleep each night where as teenagers and infants need 9.5 hours and 16 hours per day respectively. ${ }^{10}$ When sleep duration is less than 7 hours then it is characterised as short sleep in adults. Studies in the past reported that obesity from sleep deprivation is a result of interplay between several factors like changes in the eating patterns with a stronger preference for fatty foods, increased opportunities for snacking and late night meals when being awake and fatigue. ${ }^{11}$ On the whole sleep deprivation causes increased food and energy intake. ${ }^{12} \mathrm{It}$ is due to changes in the levels of neuropeptides involved in the regulation of appetite. ${ }^{13,14}$ 
Physical activity (PA) means any body movements produced by muscles that result in increased energy expenditure. It influences the sleep duration as well as maintain energy expenditure of the body thus has a direct and indirect role in preventing obesity. ${ }^{15}$ Obesity has been classified on the basis of Body mass index (BMI), however Asian population represented a special subgroup where BMI did not accurately reflect underlying adiposity ${ }^{16}$ In such situations Bio Impedance Analysis (BIA) is an alternative to BMI which is more accurate in predicting body composition and body fat $\%(\mathrm{BF} \%)$ as compared to BMI. Fat per cent below the average is associated with malnutrition and above average may lead to diseases associated with obesity.

Keeping this in mind the present study aimed to study the effect of sleep duration and physical activity on important body composition parameters.

\section{MATERIALS AND METHODS}

An observational study was conducted on the students admitted to MBBS $1^{\text {st }}$ professional at Sri Aurobindo Medical College and Post Graduate Institute, Indore. A total of 98 subjects of both sexes, aged between 17 and 27 years were selected for the study by using a purposive sampling technique. After informing the aim of the study and detailed study protocol, informed written consent was obtained from the participants.

Anthropometric measurements were taken using standardized equipments. Height of all participants were measured using a stadiometer (Seca 201 Germany) in standing position without footwear to the nearest $0.1 \mathrm{~cm}$. Weight was measured with minimum clothes using a calibrated electronic scale with digital readout (Seca 808 Germany) to the nearest $0.1 \mathrm{~kg}$. BMI was calculated by weight $(\mathrm{kg})$ divided by height $(\mathrm{m})$ squared $\left(\mathrm{kg} / \mathrm{m}^{2}\right)$.

The sleep questionnaire was designed from standard sleep medicine text book to obtain information of various sleep parameters like total time spent in bed, time to go to bed, wake up time and time to leave bed. ${ }^{17}$ On the basis of total sleep time the study subjects were divided into two categories Inadequate sleep duration (IASDN) i.e $<7$ hours of sleep duration/night and ASDN (adequate sleep duration) i.e $\geq 7$ hours of sleep duration/night. ${ }^{10}$.

BIA derived body composition analysis was done by using a commercially available single frequency 8 electrode bio impedance analyzer system (BC-418, Tanita Corp,Tokyo, Japan). The system consisted of two handgrips with two electrodes each and a footplate with four electrodes. During the measurement, the instrument recorded whole body impedance from the hands to the feet by applying an electric alternating current flux of $0.8 \mathrm{~mA}$ at an operating frequency of $50 \mathrm{kHz}$. Finally, BF\% was calculated from the whole body impedance value and the pre-entered personal data (age, gender, height and weight) of the corresponding subject. $\mathrm{BF} \%$ was estimated to the nearest $0.1 \%$. Whole body composition was estimated using standard equations provided by the BIA manufacturer. Increased $\mathrm{BF}$, high $\mathrm{BF}$ and very high $\mathrm{BF}$ were defined as $>30 \%, \geq 35 \%$ and $\geq 40 \%$ in females and $\geq 20 \%, \geq 25 \%$ and $\geq 30 \%$ in males. ${ }^{18}$

All procedures were carried out according to manufacturer's instructions. The reliability and validity of this system in measuring $\mathrm{BF} \%$ has been previously verified in studies carried out on multiple ethnic groups. It has been reported that the $\mathrm{BF} \%$ calculated by BIA was not significantly different from dual energy X-ray absorptiometry and hydrostatic weighing. ${ }^{19}$

All measurements were taken during morning hours (08301200) and the subjects were instructed to have strict control on food and fluid intake prior to the BIA measurements. Further they didn't have any vigorous activity during the preceding 12 hours of the measurement. Since the conductance of the body tissues is mainly determined by the amount of water present in fat free mass.

Physical activity level was determined by the General Practioners Physical Activity Questionnaire (GPPAQ) and the subjects were divided as Inactive, moderately inactive, moderately active and active group. ${ }^{20}$

\section{Ethics}

The procedures followed were in accordance with the rules and regulation of the ethical committee and with the Helsinki Declaration of 1975, as revised in 1983.

\section{Statistical analysis}

Continuous variables are expressed as mean \pm standard deviation (or range) while the results on categorical measurements are presented in numbers (\%). The Pearson's Chi-Square test was used to observe the association of body fat percent of boys and girls with sleep duration and physical activity. Assuming the normality of the distribution independent sample, t-test was used to identify the significance of mean differences in certain body composition parameters according to sleep duration (Adequate: $\geq$ seven hours and Inadequate: <seven hours) at night. Comparison in age, sleep duration and certain important body composition parameters impacted by physical activity was carried out using one-way analysis of variance (ANOVA). The data was analyzed by using statistical software SPSS version 17.0 trial. The probability value $\mathrm{p} \leq 0.05$ was 
considered as significant while $\mathrm{p} \leq 0.01$ and above were considered as highly significant.

\section{RESULTS}

Out of a total of 98 subjects, $40(40.8 \%)$ subjects were boys and $58(59.2 \%)$ were girls. The age of subjects obtained with a range from 17 to 27 years with a mean spread (mean $\pm \mathrm{SD}$ ) of age among boys was $19.58 \pm 2.41$ years while $18.41 \pm 1.06$ years recorded among girls.

On comparing the subcategories of $\mathrm{BF} \%$ in boys a significant association was noted to sleep duration at night ( $p=0.05$, but not with the physical activity levels $(p=0.604)$. In girls no such relationship was noted with sleep duration at night $(p=0.116)$ or physical activity levels $(p=0.604)$. Thus the effect of sleep duration on $\mathrm{BF} \%$ has showed a gender difference. The IASDN group of boys significantly differed in $\mathrm{BF} \%, \mathrm{BMI}$ and muscle mass when compared with group of boys of ASDN (Table 1). However other body composition parameters such as fat free mass, bone mass and visceral fat level didn't reach statistical significance $(\mathrm{p}>0.05)$. The results suggests that age, total sleep time at night, body fat $\%$, body mass index and muscle mass among boys were the statistically significant indicators of sleep duration at night, whereas in girls total sleep time at night, $\mathrm{BF} \%$ and $\mathrm{BMI}$ were the significant indicators of sleep duration at night (Table 2).

A highly significant difference in $\mathrm{BF} \%$ and $\mathrm{BMI}$ was noted with Physical activity levels (Table 3), but total sleep time, muscle mass, fat free mass, bone mass and visceral fat did not reach up to the level of significance $(p>0.05)$.

\section{DISCUSSION}

In the present study an inverse association between sleep duration at night and obesity parameters like $\mathrm{BMI}$ and $\mathrm{BF} \%$ was observed. $\mathrm{BF} \%$ had shown significant bonding with sleep duration at night in the boys while it was not seen in girls population in both IASDN and ASDN groups. These findings are in accordance with the findings of other cross-sectional studies from diverse locations (America, Australia, Canada, Portugal, Turkey and Japan) in which a significant inverse relationship of adiposity parameters (specifically BMI) with sleep duration was observed in boys but not in girls. ${ }^{21-24}$ In some of the studies ${ }^{25,26}$ no such association was reported whereas others have reported statistically significant inverse prospective associations between sleep duration and adiposity in both the genders. ${ }^{27}$ The observed difference might be due to the fact that the girls may be more resilient to sleep debt ${ }^{22}$ or gender differences may exists in sleep architecture with adolescent

\begin{tabular}{|c|c|c|c|}
\hline \multirow[t]{2}{*}{ Parameter } & \multicolumn{2}{|c|}{ Mean \pm std. deviation } & \multirow[t]{2}{*}{$p$ value } \\
\hline & $\begin{array}{l}\text { IASDN } \\
\left(n_{1}=12\right)\end{array}$ & $\begin{array}{c}\text { ASDN } \\
\left(n_{2}=28\right)\end{array}$ & \\
\hline Age (years) & $20.83 \pm 2.59$ & $19.04 \pm 2.15$ & $\mathrm{p}=0.028^{*}$ \\
\hline Total sleep time (hour) & $6.00 \pm 0.00$ & $7.46 \pm 0.58$ & $p=0.000^{* *}$ \\
\hline Body fat (\%) & $26.22 \pm 10.11$ & $20.23 \pm 7.17$ & $p=0.039^{*}$ \\
\hline Body mass index $\left(\mathrm{kg} / \mathrm{m}^{2}\right)$ & $25.93 \pm 5.38$ & $22.41 \pm 3.75$ & $p=0.022^{*}$ \\
\hline Muscle mass (\%) & $70.53 \pm 9.97$ & $76.41 \pm 6.84$ & $p=0.037^{*}$ \\
\hline Fat free mass $(\mathrm{kg})$ & $52.81 \pm 8.20$ & $52.00 \pm 7.59$ & $\mathrm{p}=0.765^{\otimes}$ \\
\hline Bone mass $(\mathrm{kg})$ & $2.78 \pm 0.39$ & $2.76 \pm 0.37$ & $p=0.912^{\otimes}$ \\
\hline Visceral fat level & $6.17 \pm 4.13$ & $5.11 \pm 3.17$ & $\mathrm{p}=0.382^{\otimes}$ \\
\hline
\end{tabular}

**Mean difference is highly significant at the 0.000 level of significance. *Mean difference is significant at the 0.05 and above levels of significance. ${ }^{\otimes}$ Mean difference is not significant (insignificant) at 0.05 and various lower levels of significance

\begin{tabular}{|c|c|c|c|}
\hline \multirow[t]{2}{*}{ Parameter } & \multicolumn{2}{|c|}{ Mean \pm std. deviation } & \multirow[t]{2}{*}{$\mathrm{p}$ value } \\
\hline & $\begin{array}{l}\text { IASDN } \\
\left(n_{1}=27\right)\end{array}$ & $\begin{array}{r}\text { ASDN } \\
\left(n_{2}=31\right)\end{array}$ & \\
\hline Age (years) & $18.44 \pm 0.80$ & $18.39 \pm 1.26$ & $\mathrm{p}=0.839^{\otimes}$ \\
\hline Total sleep time (hour) & $5.93 \pm 0.27$ & $7.32 \pm 0.79$ & $p=0.000^{\star \star}$ \\
\hline Body fat (\%) & $36.48 \pm 6.02$ & $32.41 \pm 8.34$ & $p=0.040^{\star}$ \\
\hline Body mass index $\left(\mathrm{kg} / \mathrm{m}^{2}\right)$ & $24.95 \pm 4.46$ & $21.99 \pm 4.79$ & $p=0.019$ * \\
\hline Muscle mass (\%) & $62.86 \pm 14.51$ & $63.76 \pm 8.06$ & $\mathrm{p}=0.767^{\otimes}$ \\
\hline Fat free mass $(\mathrm{kg})$ & $39.07 \pm 9.44$ & $38.78 \pm 5.11$ & $\mathrm{p}=0.883^{\circledR}$ \\
\hline Bone mass $(\mathrm{kg})$ & $2.17 \pm 0.56$ & $2.24 \pm 0.45$ & $\mathrm{p}=0.607^{\otimes}$ \\
\hline Visceral fat level & $4.63 \pm 3.84$ & $4.52 \pm 3.64$ & $p=0.908^{\otimes}$ \\
\hline
\end{tabular}

$* *$ Mean difference is highly significant at the 0.000 level of significance. *Mean difference is significant at the 0.05 and above levels of significance. ${ }^{\otimes}$ Mean difference is not significant (insignificant) at 0.05 and various lower levels of significance

girls experiencing proportionately more slow-wave sleep than boys, thereby reducing girls sleep need. ${ }^{21}$

Significantly higher $\mathrm{BMI}$ and $\mathrm{BF} \%$ was observed in IASDN group of boys when compared to ASDN group (Table 1). In girls similar findings were observed in both the groups (Table 2). Spiegel et al in 2004 in his study showed that sleep duration or chronic sleep debt is associated with increased hunger and appetite, especially for calorie-dense foods with high carbohydrate content. ${ }^{13}$ Curtailment in sleep duration cause obesity through biological and behavioral pathways. Several experimental studies have demonstrated how sleep restriction is linked to alterations in the production of hormones that control appetite such as leptin and ghrelin, which may lead to subsequent weight gain. ${ }^{13,28}$ Short sleep duration can lead to obesity by not only increasing appetite, the time available to eat, but also by decreasing energy expenditure by increasing fatigue and decreased physical activity. $^{29}$

Visceral fat which is considered as the marker of obesity, reportedly found to be increased in sleep deprived individuals. Hairston et al. proposed that a sleep duration 
Table 3: Impact of physical activity on important body composition parameters of the study group

\begin{tabular}{|c|c|c|c|c|c|}
\hline \multirow[t]{3}{*}{ Variable } & \multicolumn{4}{|c|}{ Physical activity } & \multirow{3}{*}{$\begin{array}{c}\text { p-value } \\
\text { (F-statistic) }\end{array}$} \\
\hline & \multicolumn{4}{|c|}{ Mean $\pm S D$} & \\
\hline & Inactive & Moderately inactive & Moderately active & Active & \\
\hline TST (hour) & $6.74 \pm 1.09$ & $6.82 \pm 0.77$ & $6.79 \pm 0.71$ & $6.95 \pm 0.95$ & $\mathrm{p}=0.884^{\otimes}$ \\
\hline $\mathrm{BF}(\%)$ & $34.04 \pm 8.65$ & $28.74 \pm 9.02$ & $25.09 \pm 11.91$ & $26.72 \pm 8.82$ & $\mathrm{p}=0.007^{*}$ \\
\hline BMI $\left(\mathrm{kg} / \mathrm{m}^{2}\right)$ & $25.55 \pm 3.94$ & $25.64 \pm 4.28$ & $20.66 \pm 4.20$ & $19.58 \pm 2.70$ & $p=0.000^{*}$ \\
\hline MM (kg) & $64.76 \pm 8.98$ & $69.36 \pm 9.48$ & $68.55 \pm 18.80$ & $70.37 \pm 8.59$ & $\mathrm{p}=0.304^{\otimes}$ \\
\hline FFM (kg) & $42.78 \pm 9.75$ & $43.93 \pm 9.33$ & $42.44 \pm 7.76$ & $49.22 \pm 11.90$ & $p=0.096^{\otimes}$ \\
\hline $\mathrm{BM}(\mathrm{kg})$ & $2.41 \pm 0.52$ & $2.39 \pm 0.53$ & $2.31 \pm 0.43$ & $2.66 \pm 0.57$ & $\mathrm{p}=0.178^{\otimes}$ \\
\hline V Fat & $5.45 \pm 4.23$ & $5.32 \pm 4.07$ & $4.58 \pm 3.19$ & $3.85 \pm 1.81$ & $\mathrm{p}=0.406^{\otimes}$ \\
\hline
\end{tabular}

*The mean differences are highly significant at the 0.007 and 0.000 levels of significance. ${ }^{\otimes}$ The mean differences are not significant at the 0.05 and below levels of significance. SD: Standard deviation, TST: Total sleep time, BF: Body fat, BMI: Body mass index, MM: Muscle mass, FFM: Fat free mass, BM: Bone mass, V Fat: Visceral fat level, $P$ value: Based on F-statistic

of 5 hours or less was associated with an increase in BMI as well as visceral and subcutaneous fat accumulation. ${ }^{30}$ In the present study visceral fat did not show significant difference either in boys or girls of ISDN or ASDN groups (Tables 1 and 2)

Physical activity is an important determinant of $\mathrm{BF} \%$ and visceral fat and it affects the sleep time as well. It has been proposed that less sleep increases BMI by decreasing physical activity as a consequence of fatigue and changes in hormones that regulate energy expenditure. ${ }^{29}$ Low physical activity is an important predictor of overweight/ obesity because it decreases energy expenditure. ${ }^{31}$ In the present study the subjects were grouped according to their physical activity level as inactive, moderately inactive, moderately active and active. On analysis of the data the noted differences in $\mathrm{BF} \%$ and $\mathrm{BMI}$ with respect to Physical activity levels was highly significant (Table 3). It was reported in the past that daily physical activity for $\geq 60$ minutes is associated with sufficient sleep among adolescents. ${ }^{15}$ In this highly advanced era everyday life offers fewer opportunities for physical activity and the resultant sedentary lifestyles have serious consequences on physical fitness and health of the society in general and to the young generation in particular, which gradually alter their body composition and predisposes to obesity and its complications.

\section{CONCLUSION}

In the present study an inverse association was seen between sleep duration at night and $\mathrm{BF} \% . \mathrm{BF} \%$ of boy's population had a significant bonding with sleep duration at night while it was not seen in girls population of both IASDN and ASDN groups. Significantly higher BMI and $\mathrm{BF} \%$ was observed in IASDN group of boys and girls when compared to ASDN groups. Significant difference was observed in $\mathrm{BF} \%$ and $\mathrm{BMI}$ of the entire study group on comparing with different categories of physical activity.

\section{ACKNOWLEDGEMENT}

1. Students of First prof. MBBS.

2. Dr. Balkishan Sharma Associate Professor of Biostatistics.

\section{REFERENCES}

1. Krueger JM and Obal F. Sleep function. Front Biosci 2003; 8: d511-d519.

2. Benington $\mathrm{JH}$. Sleep homeostasis and the function of sleep. Sleep 2000; 23: 959-966.

3. Taheri S. The link between short sleep duration and obesity: We should recommend more sleep to prevent obesity. Arch Dis Child 2006; 91: 881-884.

4. Sun $Y$, Sekine $M$ and Kagamimori S. Lifestyle and overweight among Japanese adolescents: The Toyama Birth Cohort Study. J Epidemiol 2009; 19: 303-310.

5. Shaikh WA, Patel M and Singh S. Sleep deprivation predisposes Gujarati Indian adolescents to obesity. Indian J Community Med 2009; 34: 192-191.

6. Gangwisch JE, Melaspina D, Bodex-Albala B and Heymsfield SB. Inadequate Sleep as a risk factor for Obesity: Analysis of the NHANES I. Sleep 2005; 28:1289-1296.

7. Yu Y, Lu BS, Wang B, Wang H, Yang J, Li Z, et al. Short Sleep Duration And Adiposity In Chinese Adolescents. Sleep 2007; 30:1688-1697.

8. Reynolds $\mathrm{K}$ and $\mathrm{He} \mathrm{J}$. Epidemiology of the metabolic syndrome. American Journal of the Medical Sciences 2005; 330(6): 273-279.

9. Knutson KL, Van Cauter E, Rathouz PJ, DeLeire $T$ and Lauderdale DS. Trends in the prevalence of short sleepers in the USA: 1975-2006. Sleep 2010; 33: 37-45.

10. Ferrara M and Gennaro LD. How much sleep do we need? Sleep Med Rev 2001; 5: 155-179.

11. Weiss A, Xu F, Storfer-Isser A, Thomas A, levers-Landis CE and Redline $S$. The association of sleep duration with adolescents fat and carbohydrate consumption. Sleep 2010; 33 (9): 1201-1209.

12. Nedeltcheva AV, Kilkus JM, Imperial J, Kasza K, Schoeller DA and Penev PD. Sleep curtailment is accompanied by increased intake of calories from snacks. Am J Clin Nutr 2009; 89: 126-133.

13. Spiegel K, Tasali, E., Penev, P. and Van Cauter, E. Brief communication: Sleep curtailment in healthy young men is associated with decreased leptin levels, elevated ghrelin levels, and increased hunger and appetite. Ann Intern Med 2004; 141: 846-850. 
14. Taheri S, Lin L, Austin D, Young T and Mignot E. Short sleep duration is associated with reduced leptin, elevated ghrelin and increased body mass index. PLoS Med 2004; 1(3):e62.

15. Foti KE, Eaton DK, Lowry $R$ and McKnight-Ely LR. Sufficient sleep, physical activity, and sedentary behaviors. Am J Prev Med 2011; 41(6):596-602.

16. Nishida C. Appropriate body-mass index for Asian populations and its implications for policy and intervention strategies. Lancet 2004; 363:157-163.

17. Malow BA. Approach to the patient with disordered sleep. In: Kryger MH, RothT, Dement WC, editors. Principles and practice of sleep medicine. Philadelphia, PA Elsevier Saunders; 2005:589-93.

18. Ko GTC, Tang J, Chan JCN, Sung R, Wu MMF. Wai HPS, et al. Lower BMI cut-off value to define obesity in Hong Kong Chinese: An analysis based on body fat assessment by bioelectric impedance. British Journal of Nutrition 2001; 85: 239-242.

19. Gupta N, Balasekaran G, Victor Govindaswamy V, Hwa CY and Shun LM. Comparison of body composition with bioelectric impedance (BIA) and dual energy X-ray absorptiometry (DEXA) among Singapore Chinese. J Sci Med Sport 2011; 14(1):33-35.

20. Department of Health. The General Practice Physical Activity Questionnaire: A Screening tool to assess adult physical activity levels, within primary care. 2009 [https://www.gov.uk/ government/uploads/system/uploads/attachment_data/file/ 192453/GPPAQ].

21. Knutson KL. Sex differences in the association between sleep and body mass index in adolescents. J Pediatr 2005; 147:830-834.

22. Eisenmann JC, Ekkekakis $P$ and Holmes M. Sleep duration and overweight among Australian children and adolescents. Acta Paediatr 2006; 95:956-963.
23. Ramos $\mathrm{E}$ and Barros $\mathrm{H}$. Family and school determinants of overweight in 13-year-old Portuguese adolescents. Acta Paediatr 2007; 96:281-286.

24. Ozturk A, Mazicioglu M, Poyrazoglu S, Cicek B, Gunay O, Kurtoglu $\mathrm{S}$, et al. The relationship between sleep duration and obesity in Turkish children and adolescents. Acta Paediatr 2009; 98:699-702.

25. Calamaro CJ, Park S, Mason TB, Marcus CL, Weaver TE, Pack A, et al. Shortened sleep duration does not predict obesity in adolescents. J Sleep Res 2010; 19:559-566.

26. Lytle LA, Murray DM and Laska MN. Examining the longitudinal relationship between change in sleep and obesity risk in adolescents. Health Educ Behav 2013; 40:362-370.

27. Seegers V, Petit D, Falissard B, Vitaro F, Tremblay RE, Montplaisir JSeegers $\mathrm{V}$, et al. Short sleep duration and body mass index: A prospective longitudinal study in preadolescence. Am J Epidemiol 2011; 173:621-629.

28. Omisade A, Buxton OM and Rusak B. Impact of acute sleep restriction on cortisol and leptin levels in young women. Physiol Behav 2010; 99 (5): 651-656.

29. Knutson $\mathrm{K}$ and Van Cauter E. Associations between sleep loss and increased risk of obesity and diabetes. Ann N Y Acad Sci 2008; 1129:287-304.

30. Hairston KG, Vitolins MZ, Norris JM, Anderson AM, Hanley AJ, Wagenknecht LE, et al. Sleep duration and fiveyear abdominal fat accumulation in a minority cohort: The IRAS family study. Sleep 2010; 33:289-295.

31. Pate RR, O'Neill JR, Liese AD, Janz KF, Granberg EM, Colabianchi $\mathrm{N}$, et al. Factors associated with development of excessive fatness in children and adolescents: A review of prospective studies. Obes Rev 2013;14:645-658. 